\title{
Comparison of overall survival on surgical resection versus transarterial chemoembolization with or without radiofrequency ablation in intermediate stage hepatocellular carcinoma: A propensity score matching analysis
}

Chih-Wen Lin

E-DA Hospital, I-Shou University https://orcid.org/0000-0003-2344-5056

\section{Yaw-Sen Chen}

E-Da Hospital, I-Shou University

Gin-Ho Lo

E-Da hospital, I-Shou University

Yao-Chun Hsu

E-Da hospital, I-Shou University

Chia-Chang Hsu

E-Da hospital, I-Shou University

\section{Tsung-Chin Wu}

E-Da Dachang hospital, I-Shou University

Jen-Hao Yeh

E-Da Dachang Hospital, I-Shou University

\section{Pojen Hsiao}

E-Da Dachang, I-Shou University

Pei-Min Hsieh

E-Da hospital, I-Shou University

Hung-Yu Lin

E-Da Cancer Hospital, I-Shou University

Chih-Wen Shu

I-Shou University

Chao-Ming Hung ( $\nabla$ ed1001968@edah.org.tw )

Research article

Keywords: Hepatocellular carcinoma; Barcelona Clinic Liver Cancer stage B; Overall survival; Surgical resection; Transcatheter arterial chemoembolization; Radiofrequency ablation 
Posted Date: March 13th, 2020

DOI: https://doi.org/10.21203/rs.2.22284/v2

License: (c) (i) This work is licensed under a Creative Commons Attribution 4.0 International License. Read Full License

Version of Record: A version of this preprint was published at BMC Gastroenterology on April 10th, 2020. See the published version at https://doi.org/10.1186/s12876-020-01235-w. 


\section{Abstract}

Background: Patients with Barcelona Clinic Liver Cancer (BCLC) stage B hepatocellular carcinoma (HCC) are recommended to undergo transcatheter arterial chemoembolization (TACE). However, TACE in combination with radiofrequency ablation (RFA) is not inferior to surgical resection (SR), and the benefits of surgical resection (SR) for BCLC stage B HCC remain unclear. Hence, this study aims to compare the impact of SR, TACE+RFA, and TACE on analyzing overall survival (OS) in BCLC stage B HCC. Methods: Overall, $428 \mathrm{HCC}$ patients were included in BCLC stage B, and their clinical data and OS were recorded. OS was analyzed by the Kaplan-Meier method and Cox regression analysis. Results: One hundred forty (32.7\%) patients received SR, 231 (53.9\%) received TACE+RFA, and 57 (13.3\%) received TACE. The OS was significantly higher in the SR group than that in the TACE+RFA group [hazard ratio (HR): 1.78; 95\% confidence incidence $(\mathrm{Cl}): 1.15-2.75, \mathrm{p}=0.009]$. The OS was significantly higher in the SR group than that in the TACE group (HR: 3.17; 95\% Cl: 2.31-4.36, p<0.0001). Moreover, the OS was significantly higher in the TACE+RFA group than that in the TACE group (HR: 1.82; 95\% Cl: 1.21-2.74, $p=0.004$ ). The cumulative OS rates at 1,3 and 5 years in the SR, TACE+RFA, and TACE groups were $89.2 \%, 69.4 \%$ and $61.2 \%, 86.0 \%$, $57.9 \%$ and $38.2 \%$, and $69.5 \%, 37.0 \%$ and $15.2 \%$, respectively. After propensity score matching, the SR group still had a higher OS than those of the TACE+RFA and TACE groups. The TACE+RFA group had a higher OS than that of the TACE group. Conclusion: The SR group had higher OS than the TACE+RFA and TACE groups in BCLC stage B HCC. Furthermore, the TACE+RFA group had higher OS than the TACE group.

\section{Introduction}

Hepatocellular carcinoma (HCC) is the fifth most common cancer but the third most lethal cancer worldwide[1]. The Barcelona Clinic Liver Cancer (BCLC) system is widely utilized in the American Association for the Study of Liver Disease (AASLD), European Association for the Study of Liver (EASL) and Asian-Pacific Associated for the Study of the Liver (APASL) guidelines for the treatment of HCC[2-4]. Patients with stage $B$ (intermediate stage) $\mathrm{HCC}$ are recommended to undergo transcatheter arterial chemoembolization (TACE) based on the BCLC system[2-4]. However, surgical resection (SR) and radiofrequency ablation (RFA) are curative therapies in BCLC stage 0/A and are alternative therapies for selected patients with BCLC stage $B$ in clinical practice[5-7]. Previous studies have shown that TACE combined with RFA (TACE+RFA) has a better overall survival (OS) than TACE in BCLC stage B[6, 8, 9]. Moreover, some studies have shown that SR can have a better OS than TACE with or without RFA in BCLC stage B[5-7]. However, TACE+RFA is not inferior to SR for patients with HCC within the Milan criteria[10]. Furthermore, TACE + RFA is not inferior to SR for patients with HCC within BCLC stage A or B after propensity score-based analysis[6]. Hence, this study aims to compare the impact of SR, TACE + RFA, and TACE on the OS of HCC patients with BCLC stage B. Each patient was treated with one of these three therapies. Furthermore, we compared the OS of patients in each group using propensity score matching (PSM) to minimize potential bias in the results. 


\section{Materials And Methods}

\section{Patients and follow-up}

We retrospectively collected information on 2680 patients diagnosed with HCC between 2011 and 2018 at E-Da Hospital, I-Shou University, Kaohsiung, Taiwan. Two thousand and one hundred forty-six patients were excluded due to BCLC stage $0, A, C$, and $D$, and 110 patients had incomplete data in BCLC stage $B$. Finally, 428 patients with BCLC stage B were included in this retrospective study (Figure 1). The study was conducted in accordance with the guidelines of the International Conference on Harmonization for Good Clinical Practice and was approved by the Ethics Committee of E-Da Hospital, I-Shou University (EMRP107-130). Patients were diagnosed with HCC based on histological confirmation or at least one typical imaging method according to the recommendations of the AASLD[2]. Clinicopathological parameters, including demographic data, smoking, excessive alcohol use, hepatitis status, serum total bilirubin, international normalization ratio (INR), liver cirrhosis, Child-Pugh (CP) class, tumor size, tumor number, alpha-fetoprotein (AFP), mortality, and follow-up time, were examined. Tumor number and tumor size were mostly determined based on radiologic findings and confirmed by pathologic findings if appropriate. Liver cirrhosis was diagnosed based on pathologic findings and/or evaluated by ultrasound, computed tomography (CT), or magnetic resonance imaging (MRI). The functional status of the liver was evaluated using the $\mathrm{CP}$ scoring system.

Patients were treated with SR, TACE+RFA, and TACE, and our multidisciplinary team chose suitable therapy. The criteria for SR were resectable tumors, sufficient residual liver volume, $\mathrm{CP}$ class $\mathrm{A}$ or selected $\mathrm{CP}$ class $\mathrm{B}$ patients, or absence of ascites and hypersplenism. The indications of TACE+RFA were CP class $A$ or $B$ and absent ascites. The indications of TACE were $C P$ class $A$ or $B$ and absent massive ascites. Patients were divided into the SR group, TACE+RFA group, and TACE group.

Patients were followed up every three to six months by abdominal ultrasound, CT or MRI and AFP. OS was defined as the time from the date of diagnosis to the date of death or last visit, and the last follow-up time was June 2019.

\section{Data analysis and statistics}

All statistical analyses were performed using SPSS ver. 23.0 (SPSS, Chicago, IL, USA). Numerical data were expressed as medians and ranges. Categorical data were described using numbers and percentages. OS was determined using the Kaplan-Meier method and compared with patients receiving different treatments. Cox proportional hazards regression analysis of OS in HCC patients was performed according to different treatments. Moreover, we used logistic regression to perform PSM with sex, age, cirrhosis, CP class, tumor size, and tumor number for patients to reduce bias in our analyses. Each treatment group was matched with the control group (SR group or TACE group) according to the generated PSM using a caliper width of 0.2. On the completion of matching, the baseline covariates were compared using the paired t-test or Mann-Whitney $U$ test for continuous variables and the chi-square test for categorical variables. A p-value $<0.05$ was used to determine statistical significance. 


\section{Results}

\section{Baseline demographic data before propensity score matching}

A total of $428 \mathrm{HCC}$ patients were included in this study (Figure 1). The demographic and clinical features of the 428 patients ( $77.8 \%$ male, median age of 63 years) are shown in Table 1. Regarding the etiology of $\mathrm{HCC}, 47.9 \%$ of the patients had HBV infection, $32.4 \%$ had HCV infection, and $42.3 \%$ had excessive alcohol use. Approximately $54.7 \%$ of patients had liver cirrhosis, and of those patients, $86.9 \%$ had CP class A disease. Many $(67.5 \%)$ of the patients had tumors $\geq 5 \mathrm{~cm}$ in size, and $65.0 \%$ of the patients had multiple tumors.

\section{Overall survival of patients in the total and different treatment groups}

Of the 428 patients, 257 (60.0\%) died, and the median follow-up duration was 29 (range, 1-98) months (Table 1). The mortality rate was $24.8 \%$ per person-year. The cumulative OS rates at 1,3 , and 5 years were $80.8 \%, 50.6 \%$ and $32.8 \%$, respectively (Figure $2 A$ ). Among the 428 patients, $140(32.7 \%$ ) patients received SR, 231 (53.9\%) received TACE+RFA, and 57 (13.3\%) received TACE (Table 1). The OS was significantly better in the SR group than in the TACE+RFA group (HR: 1.78; 95\% Cl: 1.15-2.75, $p=0.009$, Figure 2B). The OS was significantly better in the SR group than in the TACE group (HR: 3.17; 95\% Cl: 2.31-4.36, $p<0.0001$, Figure 2B). Moreover, the OS was significantly better in the TACE+RFA group than in the TACE group (HR: $1.82 ; 95 \% \mathrm{Cl}: 1.21-2.74, \mathrm{p}=0.004$, Figure $2 \mathrm{~B}$ ). The cumulative $\mathrm{OS}$ rates at 1,3 and 5 years in the $\mathrm{SR}$, TACE+RFA, and TACE groups were $89.2 \%, 69.4 \%$ and $61.2 \%, 86.0 \%, 57.9 \%$ and $38.2 \%$, and $69.5 \%, 37.0 \%$ and $15.2 \%$, respectively (Figure $2 \mathrm{~B}$ ).

\section{Baseline demographic data after propensity score matching}

The SR group showed significant differences compared with the TACE+RFA and TACE groups with respect to baseline features before PSM. The SR group had significantly lower rate of HCV infection cirrhosis, tumor number, and mortality, lower serum total bilirubin and INR level, and higher rate of CP class A and tumor size compared to the TACE+RFA and TACE groups $(p<0.05)($ Table 1$)$. The PSM was performed with sex, age, cirrhosis, CP class, tumor size, and tumor number, and there were no significant differences for the important features (Table 2 and 3 ).

\section{Overall survival of patients in the different treatment groups after propensity score matching}

In the SR group versus TACE+RFA group after PSM (Table 2), 140 patients underwent SR, and 16 patients received TACE+RFA. Patients undergoing SR had significantly higher survival rates than patients receiving TACE+RFA (HR: 2.33; 95\% Cl: 1.21-4.49, p=0.011, Figures $3 A$ ). The cumulative $O S$ rates at 1,3 and 5 years in the SR and TACE+RFA groups were $89.2 \%, 69.4 \%$ and $61.2 \%$ and $81.3 \%, 50.0 \%$ and $26.8 \%$, respectively (Figures 3A).

In the SR group versus TACE group after PSM (Table 2), 140 patients underwent SR, and 87 patients received TACE. Patients undergoing SR had significantly higher survival rates than patients receiving 
TACE treatments (HR: $3.10 ; 95 \% \mathrm{Cl}: 2.15-4.46, \mathrm{p}<0.0001$, Figures 3B). The cumulative OS rates at 1,3 and 5 years in the SR and TACE groups were $89.2 \%, 69.4 \%$ and $61.2 \%$ and $70.1 \%, 36.3 \%$ and $15.7 \%$, respectively (Figures 3B).

In the TACE+RFA group versus TACE group after PSM (Table 3), 56 patients received TACE+RFA, and 231 patients received TACE. Patients undergoing TACE+RFA had significantly higher survival rates than patients receiving TACE treatments (HR: $1.77 ; 95 \% \mathrm{Cl}: 1.22-2.56, p=0.002$, Figures $3 \mathrm{C}$ ). The cumulative OS rates at 1,3 and 5 years in the TACE+RFA and TACE groups were $85.7 \%, 57.1 \%$ and $37.7 \%$ and $73.5 \%$, $37.0 \%$ and $15.2 \%$, respectively (Figures $3 \mathrm{C}$ ).

\section{Abbrevitations}

HCC: Hepatocellular carcinoma; BCLC: Barcelona Clinic Liver Cancer; AASLD: American Association for the Study of Liver Disease; EASL: European Association for the Study of Liver; APASL: Asian-Pacific Associated for the Study of the Liver; SR: Surgical resection; RFA: Radiofrequency ablation; TACE: Transcatheter arterial chemoembolization; PSM: Propensity score matching; CP class: Child-Pugh class; OS: overall survival; HBV: Hepatitis B virus; HCV: Hepatitis C virus; AFP: Alpha-fetoprotein; INR: International normalize ratio; CT: Computed tomography; MRI: Magnetic resonance imaging; HR: Hazard ratio; and $\mathrm{Cl}$ : Confidence interval;

\section{Declarations}

\section{SPECIFIC AUTHOR CONTRIBUTIONS}

Lin CW, Chen YS, Lo GH, Hsu YC and Wu TC performed the experiments, recruited the patients, collected and analyzed the data, and wrote the manuscript together with Hsu CC, Yen JH, Hsiao PJ, Hsieh PM, Lin $\mathrm{HY}$, and Shu CW. Hung CM designed the study and wrote the manuscript together with Lin CW and Chen YS. All of the authors provided important suggestions pertaining to the manuscript and reviewed and approved the manuscript.

\section{ACKNOWLEDGMENTS}

This study was supported by grants from MOST (105-2314-B-650-004-MY3 and 108-2314-B-214-006MY2), the E-Da Hospital-National Taiwan University Hospital Joint Research Program (108-EDN11), and the E-Da Hospital (EDAHP108036, EDAHP108037, ECAHP108038, EDAHP109044, EDAHP109045, and, EDAHP109053) to Chih-Wen Lin.

\section{CONFLICTS OF INTEREST}

None declared.

\section{References}


1. Bertuccio P, Turati F, Carioli G, Rodriguez T, La Vecchia C, Malvezzi M, Negri E: Global trends and predictions in hepatocellular carcinoma mortality. J Hepatol 2017, 67(2):302-309.

2. Heimbach JK, Kulik LM, Finn RS, Sirlin CB, Abecassis MM, Roberts LR, Zhu AX, Murad MH, Marrero JA: AASLD guidelines for the treatment of hepatocellular carcinoma. Hepatology 2018, 67(1):358380.

3. European Association for the Study of the Liver. Electronic address eee, European Association for the Study of the L: EASL Clinical Practice Guidelines: Management of hepatocellular carcinoma. $J$ Hepatol 2018, 69(1):182-236.

4. Omata M, Cheng AL, Kokudo N, Kudo M, Lee JM, Jia J, Tateishi R, Han KH, Chawla YK, Shiina S et al: Asia-Pacific clinical practice guidelines on the management of hepatocellular carcinoma: a 2017 update. Hepatol Int 2017, 11(4):317-370.

5. Zhong JH, Xiang BD, Gong WF, Ke Y, Mo QG, Ma L, Liu X, Li LQ: Comparison of long-term survival of patients with BCLC stage B hepatocellular carcinoma after liver resection or transarterial chemoembolization. PLoS One 2013, 8(7):e68193.

6. Liu Y, Xue D, Tan S, Zhang Q, Yang X, Li Y, Zhu B, Niu S, Jiang L, Wang X: Comparison of macrovascular invasion-free survival in early-intermediate hepatocellular carcinoma after different interventions: A propensity score-based analysis. J Cancer 2019, 10(17):4063-4071.

7. Yin L, Li H, Li AJ, Lau WY, Pan ZY, Lai EC, Wu MC, Zhou WP: Partial hepatectomy vs. transcatheter arterial chemoembolization for resectable multiple hepatocellular carcinoma beyond Milan Criteria: a RCT. J Hepatol 2014, 61(1):82-88.

8. Shimose S, Tanaka M, Iwamoto H, Niizeki T, Shirono T, Aino H, Noda Y, Kamachi N, Okamura S, Nakano $\mathrm{M}$ et al: Prognostic impact of transcatheter arterial chemoembolization (TACE) combined with radiofrequency ablation in patients with unresectable hepatocellular carcinoma: Comparison with TACE alone using decision-tree analysis after propensity score matching. Hepatol Res 2019, 49(8):919-928.

9. Liu F, Chen M, Mei J, Xu L, Guo R, Lin X, Zhang Y, Peng Z: Transarterial Chemoembolization Combined with Radiofrequency Ablation in the Treatment of Stage B1 Intermediate Hepatocellular Carcinoma. J Oncol 2019, 2019:6298502.

10. Bholee AK, Peng K, Zhou Z, Chen J, Xu L, Zhang Y, Chen M: Radiofrequency ablation combined with transarterial chemoembolization versus hepatectomy for patients with hepatocellular carcinoma within Milan criteria: a retrospective case-control study. Clin Trans/ Oncol 2017, 19(7):844-852.

11. Bolondi L, Burroughs A, Dufour JF, Galle PR, Mazzaferro V, Piscaglia F, Raoul JL, Sangro B: Heterogeneity of patients with intermediate (BCLC B) Hepatocellular Carcinoma: proposal for a subclassification to facilitate treatment decisions. Semin Liver Dis 2012, 32(4):348-359.

12. Forner A, Gilabert M, Bruix J, Raoul JL: Treatment of intermediate-stage hepatocellular carcinoma. Nat Rev Clin Oncol 2014, 11(9):525-535.

13. Ho MC, Hasegawa K, Chen XP, Nagano H, Lee YJ, Chau GY, Zhou J, Wang CC, Choi YR, Poon RT et al: Surgery for Intermediate and Advanced Hepatocellular Carcinoma: A Consensus Report from the 5th 
Asia-Pacific Primary Liver Cancer Expert Meeting (APPLE 2014). Liver Cancer 2016, 5(4):245-256.

14. Guo H, Wu T, Lu Q, Li M, Guo JY, Shen Y, Wu Z, Nan KJ, Lv Y, Zhang XF: Surgical resection improves long-term survival of patients with hepatocellular carcinoma across different Barcelona Clinic Liver Cancer stages. Cancer Manag Res 2018, 10:361-369.

\section{Tables}

Table 1. Basic demographic data of patients with BCLC stage B hepatocellular carcinoma of various treatments.

\begin{tabular}{|c|c|c|c|c|c|}
\hline Variable & $\begin{array}{l}\text { SR } \\
(\mathrm{n}=140)\end{array}$ & $\begin{array}{l}\text { TACE } \\
(n=231)\end{array}$ & $\begin{array}{l}\text { TACE+RFA } \\
(n=57)\end{array}$ & $\begin{array}{l}\text { Total } \\
(\mathrm{n}=428)\end{array}$ & P-value \\
\hline Male & $\begin{array}{l}117 \\
(83.6)\end{array}$ & $173(74.9)$ & $43(75.4)$ & $333(77.8)$ & 0.134 \\
\hline Age (years) & $\begin{array}{l}62(35- \\
82)\end{array}$ & $64(29-91)$ & $64(28-86)$ & $63(25-91)$ & 0.311 \\
\hline Smoking & $68(48.6)$ & $113(48.9)$ & $27(47.4)$ & $208(48.6)$ & 0.978 \\
\hline Alcohol use & $58(41.4)$ & $100(43.3)$ & $23(40.4)$ & $181(42.3)$ & 0.894 \\
\hline HBV positive & $70(50.0)$ & $103(44.6)$ & $32(56.1)$ & $205(47.9)$ & 0.245 \\
\hline HCV positive & $30(21.4)$ & $90(39.0)$ & $21(36.8)$ & $141(32.9)$ & 0.002 \\
\hline Total Bilirubin & $\begin{array}{l}1.03 \pm \\
0.43\end{array}$ & $1.34 \pm 1.14$ & $1.40 \pm 0.66$ & $1.24 \pm 0.91$ & 0.003 \\
\hline INR & $\begin{array}{l}1.00 \pm \\
0.06\end{array}$ & $1.06 \pm 0.12$ & $1.10 \pm 0.14$ & $1.05 \pm 0.11$ & $<0.0001$ \\
\hline Cirrhosis & $36(25.7)$ & $155(67.1)$ & $43(75.4)$ & $234(54.7)$ & $<0.0001$ \\
\hline Child-Pugh class A & $\begin{array}{l}134 \\
(95.7)\end{array}$ & $194(84.0)$ & $44(77.2)$ & $372(86.9)$ & $<0.0001$ \\
\hline Tumor size & $8.2 \pm 3.3$ & $7.0 \pm 3.8$ & $5.5 \pm 2.6$ & $7.0 \pm 3.6$ & 0.001 \\
\hline Tumor size $\geq 5 \mathrm{~cm}$ & $\begin{array}{l}127 \\
(90.7) \\
\end{array}$ & $149(64.5)$ & $25(43.8)$ & $289(67.5)$ & $<0.0001$ \\
\hline Tumor number $(\geq 3)$ & $49(35.0)$ & $178(77.1)$ & $51(89.5)$ & $278(65.0)$ & $<0.0001$ \\
\hline $\operatorname{AFP}(n g / m L) \geq 200$ & $34(24.3)$ & $50(21.6)$ & $7(12.1)$ & $91(21.3)$ & 0.171 \\
\hline Mortality & $50(35.7)$ & $173(74 . .9)$ & $34(59.6)$ & $257(60.0)$ & $<0.0001$ \\
\hline $\begin{array}{l}\text { Follow-up times } \\
\text { (months) }\end{array}$ & $39(1-98)$ & $22(1-97)$ & $37(3-95)$ & $29(1-98)$ & $<0.001$ \\
\hline
\end{tabular}

BCLC stage: Barcelona clinic liver cancer; SR: Surgical resection; TACE: Transcatheter arterial chemoembolization; RFA: Radiofrequency ablation; HBV: Hepatitis B virus; HCV: Hepatitis C virus; AFP: INR: International normalize ratio; Alpha-fetoprotein;

Table 2. Comparison of surgical resection versus transarterial chemoembolization with or without radiofrequency ablation of patients withBCLC stage B hepatocellular carcinoma after propensity score matching 


\begin{tabular}{|l|l|l|l|l|l|l|}
\hline Variable & $\begin{array}{l}\text { SR } \\
(\mathrm{n}=140)\end{array}$ & $\begin{array}{l}\text { TACE+RFA } \\
(\mathrm{n}=16)\end{array}$ & P-value & $\begin{array}{l}\text { SR } \\
(\mathrm{n}=140)\end{array}$ & $\begin{array}{l}\text { TACE } \\
(\mathrm{n}=87)\end{array}$ & $\begin{array}{l}\text { P- } \\
\text { value }\end{array}$ \\
\hline Male & $\begin{array}{l}117 \\
(83.6)\end{array}$ & $13(81.3)$ & 0.220 & $\begin{array}{l}117 \\
(83.6)\end{array}$ & $67(77.0)$ & 0.813 \\
\hline Age (years) & $\begin{array}{l}62(35- \\
82)\end{array}$ & $66(35-87)$ & 0.249 & $\begin{array}{l}62(35- \\
82)\end{array}$ & $\begin{array}{l}64(36- \\
87)\end{array}$ & 0.121 \\
\hline Smoking & $\begin{array}{l}68 \\
(48.6)\end{array}$ & $8(50.0)$ & 0.472 & $\begin{array}{l}68 \\
(48.6)\end{array}$ & $38(43.7)$ & 0.914 \\
\hline Alcohol use & $\begin{array}{l}58 \\
(41.4)\end{array}$ & $7(43.8)$ & 0.858 & $\begin{array}{l}58 \\
(41.4)\end{array}$ & $35(40.2)$ & 0.858 \\
\hline HBV positive & $\begin{array}{l}70 \\
(50.0)\end{array}$ & $10(62.5)$ & 0.206 & $\begin{array}{l}70 \\
(50.0)\end{array}$ & $36(41.4)$ & 0.343 \\
\hline HCV positive & $\begin{array}{l}30 \\
(21.4)\end{array}$ & $6(16.7)$ & 0.069 & $\begin{array}{l}30 \\
(21.4)\end{array}$ & $26(29.8)$ & 0.148 \\
\hline Total Bilirubin & $\begin{array}{l}1.03 \pm \\
0.43\end{array}$ & $1.21 \pm 0.54$ & 0.186 & $\begin{array}{l}1.03 \pm \\
0.43\end{array}$ & $\begin{array}{l}1.11 \pm \\
0.50\end{array}$ & 0.061 \\
\hline INR & $\begin{array}{l}1.00 \pm \\
0.06\end{array}$ & $1.04 \pm 0.10$ & 0.061 & $\begin{array}{l}1.00 \pm \\
0.06\end{array}$ & $\begin{array}{l}1.03 \pm \\
0.09\end{array}$ & 0.051 \\
\hline Cirrhosis & $\begin{array}{l}36 \\
(25.7)\end{array}$ & $6(37.5)$ & 0.098 & $\begin{array}{l}36 \\
(25.7)\end{array}$ & $31(35.6)$ & 0.111 \\
\hline Child-Pugh class A & $\begin{array}{l}134 \\
(95.7)\end{array}$ & $14(87.5)$ & 0.236 & $\begin{array}{l}134 \\
(95.7)\end{array}$ & $80(92.7)$ & 0.158 \\
\hline Tumor size & $\begin{array}{l}8.2 \pm \\
3.3\end{array}$ & $6.6 \pm 2.8$ & 0.903 & $\begin{array}{l}8.2 \pm \\
3.3\end{array}$ & $8.2 \pm 3.5$ & 0.063 \\
\hline Tumor size $\geq 5$ cm & $\begin{array}{l}127 \\
(90.7)\end{array}$ & $12(75.0)$ & 0.186 & $\begin{array}{l}127 \\
(90.7)\end{array}$ & $75(86.2)$ & 0.071 \\
\hline Tumor number $(\geq 3)$ & $\begin{array}{l}49 \\
(35.0)\end{array}$ & $9(56.2)$ & 0.075 & $\begin{array}{l}49 \\
(35.0)\end{array}$ & $41(47.1)$ & 0.058 \\
\hline AFP (ng/mL) $\geq 200$ & $\begin{array}{l}34 \\
(24.3)\end{array}$ & $2(12.5)$ & 0.405 & $\begin{array}{l}34 \\
(24.3)\end{array}$ & $17(19.5)$ & 0.289 \\
\hline Mortality & $\begin{array}{l}50 \\
(35.7)\end{array}$ & $11(68.8)$ & $<0.0001$ & $\begin{array}{l}50 \\
(35.7)\end{array}$ & $70(80.5)$ & 0.010 \\
\hline $\begin{array}{l}\text { Follow up times } \\
\text { (months) }\end{array}$ & $\begin{array}{l}39(1- \\
98)\end{array}$ & $26(9-76)$ & $<0.0001$ & $\begin{array}{l}39(1- \\
98)\end{array}$ & $21(2-97)$ & 0.240 \\
\hline
\end{tabular}

BCLC stage: Barcelona clinic liver cancer; SR: Surgical resection; TACE: Transcatheter arterial chemoembolization; RFA: Radiofrequency ablation; HBV: Hepatitis B virus; HCV: Hepatitis C virus; AFP: INR: International normalize ratio; Alpha-fetoprotein;

Table 3. Comparison of transarterial chemoembolization with radiofrequency ablation versus transarterial chemoembolization of patients with BCLC stage B hepatocellular carcinoma after propensity score matching 


\begin{tabular}{|l|l|l|l|}
\hline Variable & TACE+RFA (n=56) & TACE $(\mathrm{n}=231)$ & P-value \\
\hline Male & $42(75.0)$ & $173(74.9)$ & 0.987 \\
\hline Age (years) & $64(28-86)$ & $64(29-91)$ & 0.672 \\
\hline Smoking & $27(47.4)$ & $113(48.9)$ & 0.925 \\
\hline Alcohol use & $23(40.4)$ & $100(43.3)$ & 0.763 \\
\hline HBV positive & $32(56.1)$ & $103(44.6)$ & 0.091 \\
\hline HCV positive & $21(36.8)$ & $90(39.0)$ & 0.085 \\
\hline Total Bilirubin & $1.41 \pm 0.67$ & $1.34 \pm 1.14$ & 0.643 \\
\hline INR & $1.10 \pm 0.14$ & $1.06 \pm 0.12$ & 0.060 \\
\hline Cirrhosis & $43(75.4)$ & $155(67.1)$ & 0.160 \\
\hline Child-Pugh class A & $43(76.8)$ & $194(84.0)$ & 0.203 \\
\hline Tumor size & $5.5 \pm 2.6$ & $7.0 \pm 3.8$ & 0.062 \\
\hline Tumor size $\geq 5$ cm & $25(44.6)$ & $149(64.5)$ & 0.053 \\
\hline Tumor number $(\geq 3)$ & $50(89.3)$ & $178(77.1)$ & 0.051 \\
\hline AFP (ng/mL) $\geq 200$ & $6(10.7)$ & $50(21.6)$ & 0.064 \\
\hline Mortality & $34(59.6)$ & $173(74 . .9)$ & 0.034 \\
\hline Follow up times (months) & $36(3-95)$ & $22(1-97)$ & $<0.0001$ \\
\hline
\end{tabular}

BCLC stage: Barcelona clinic liver cancer; SR: Surgical resection; TACE: Transcatheter arterial chemoembolization; RFA: Radiofrequency ablation; HBV: Hepatitis B virus; HCV: Hepatitis C virus; AFP: INR: International normalize ratio; Alpha-fetoprotein;

\section{Figures}




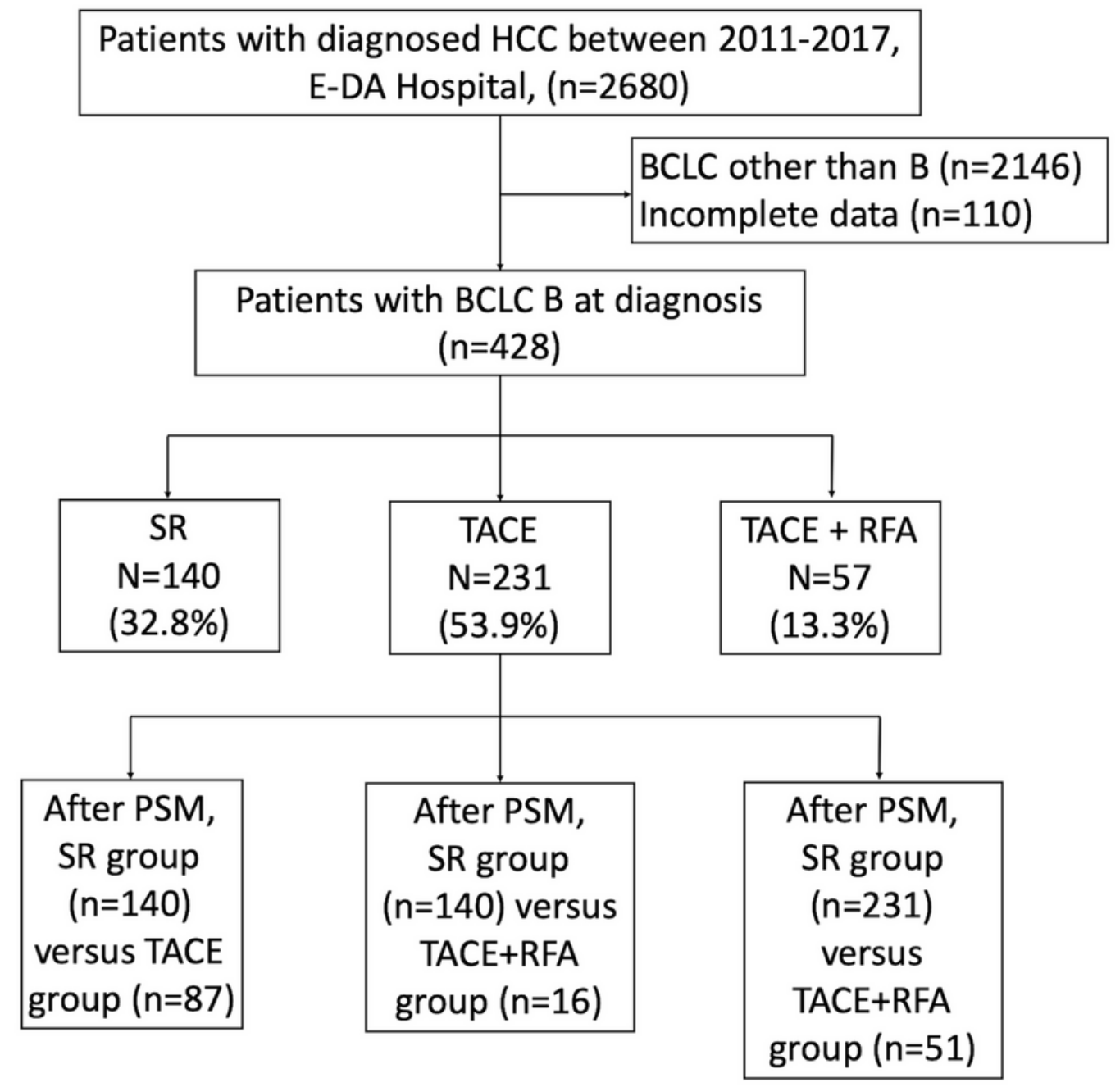

Figure 1

Study flowchart and inclusion of participants. 
A

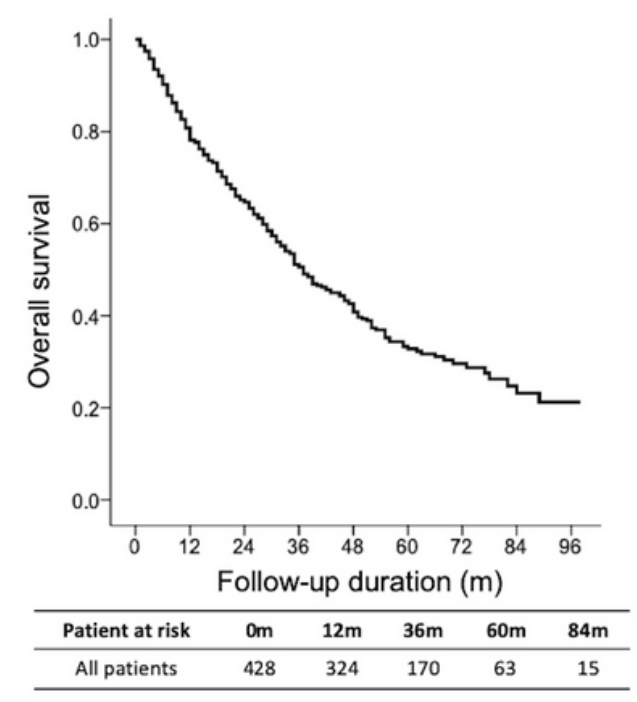

B

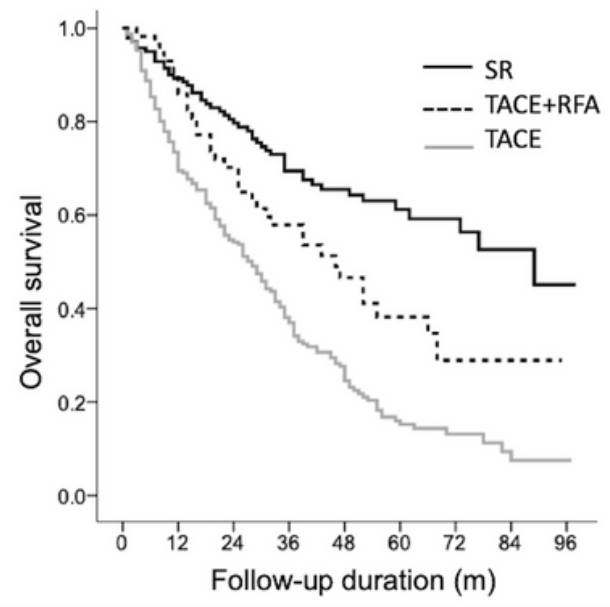

\begin{tabular}{cccccccc}
\hline Patient at risk & $\mathbf{0 m}$ & $\mathbf{1 2 m}$ & $\mathbf{3 6 m}$ & $\mathbf{6 0 m}$ & $\mathbf{8 4 m}$ & P-value & HR $(\mathbf{9 5 \%} \mathrm{CI})$ \\
\hline SR & 140 & 121 & 76 & 32 & 9 & Ref. & 1 \\
TACE & 231 & 154 & 65 & 19 & 4 & $<0.0001$ & $3.17(2.31-4.36)$ \\
TACE+RFA & 57 & 49 & 29 & 12 & 2 & 0.009 & $1.78(1.15-2.75)$ \\
\hline
\end{tabular}

Figure 2

Overall survival in Barcelona Clinic Liver Cancer stage B hepatocellular carcinoma (HCC) patients. Overall survival in all $428 \mathrm{HCC}$ patients (A). Overall survival based on Cox regression analysis in HCC patients with different treatments before propensity score matching $(B)$. 


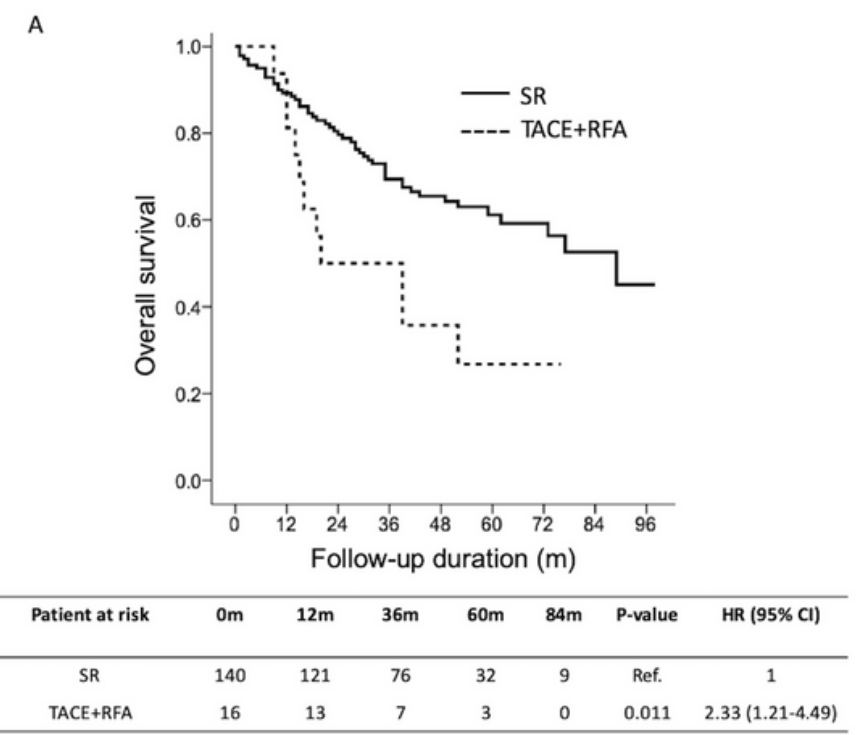

B
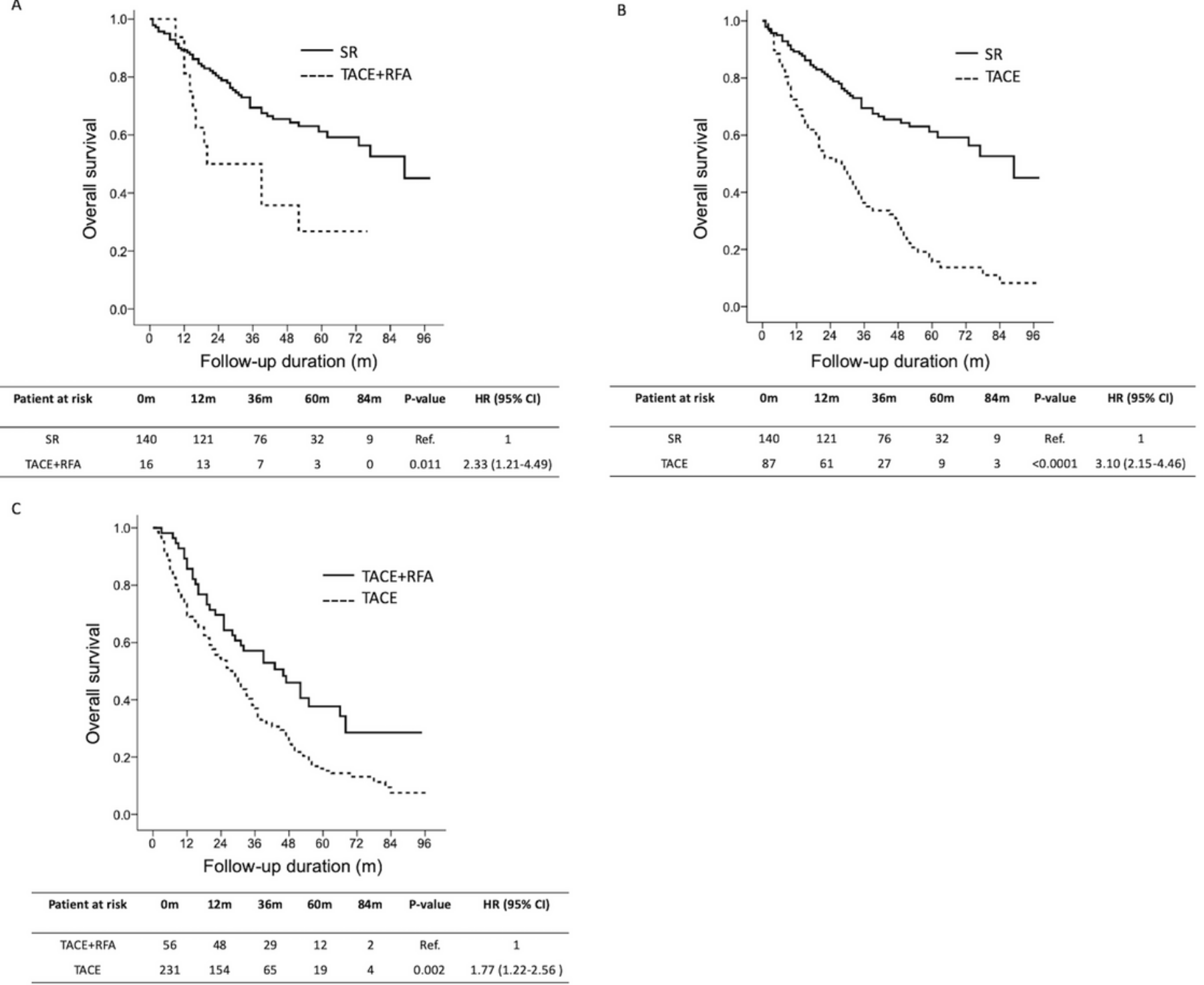

\section{Figure 3}

Overall survival according to different treatments after propensity score matching. Comparison of overall survival between surgical resection (SR) versus transarterial chemoembolization (TACE) with radiofrequency ablation (RFA) (A). Comparison of overall survival between SR versus TACE (B). Comparison of overall survival between TACE+RFA versus TACE (C). 